\title{
NMR Spectral Studies of Some Six-membered and Seven-membered Saturated Hetero Cyclic Compounds - Homopiperazin - 5 - Ones
}

\author{
G. Mathubala and V. Krishnasamy \\ Bharath University, Selaiyur, Chennai-600 073, India; madhu2705@gmail.com, nadippi@gmail.com
}

\begin{abstract}
Some six and seven membered saturated hetero cyclic compounds were prepared. ${ }^{1} \mathrm{H}$ NMR spectra were recorded in DMSO $-d_{6}$. The chemical shifts were compared with those in $\mathrm{CDCl}_{3}$. The COSY, NOESY and ${ }^{13} \mathrm{C}^{-1} \mathrm{H}$ correlation spectra had been recorded to assign the signals unambiguously. The coupling constant of benzylic proton with one of the vicinal proton was found to be zero. The buttressing effect of alkyl groups was also studied. The chemical shift values, area of the signals, multiplicity, COSY and NOESY spectra were used to assign the signals. Further COSY and NOESY and ${ }^{13} \mathrm{C}^{-1} \mathrm{H}$ correlation spectra were also used. The solvent effect, concentration effect, and temperature effect were also studied using DMSO- $\mathrm{d}_{6}$ and $\mathrm{CDCl}_{3} \alpha$ - effect and polar nature of the neighbouring group were also studied.
\end{abstract}

Keywords: Assignment, Chemical Shift, Correlation, Isopropyl, Multiplets, NOE, Peak, Signal

\section{Intoduction}

Ever since Barton pointed out the importance of conformational analysis, there has been a rapid development in the conformational analysis of various systems. Nuclear magnetic resonance spectroscopy is a powerful tool for such analysis. ${ }^{1} \mathrm{H},{ }^{13} \mathrm{C},{ }^{15} \mathrm{~N},{ }^{17} \mathrm{O}$ and ${ }^{33} \mathrm{~S}$ are the nuclei used for analysis. ${ }^{1}$ Nowadays $2-\mathrm{D}-\mathrm{NMR}$ spectroscopy is also used for structural diagnosis.

\section{2. ${ }^{1} \mathrm{H}$ NMR Spectroscopy}

The important measurables in the ${ }^{1} \mathrm{H}$ NMR spectra are Chemical Shifts and Constants.

\section{2. $1{ }^{1} \mathrm{H}$ Chemical Shift}

Chemical shift of a proton is affected by the electron density around it; the higher the electron density, the higher the field of absorption. The chemical shifts for $\mathrm{CH}_{3} \mathrm{I}$, $\mathrm{CH}_{3} \mathrm{Br}, \mathrm{CH}_{3} \mathrm{Cl}$, and $\mathrm{CH}_{3} \mathrm{~F}$ are 2.16, 2.68, 3.05 and 4.26 ppm respectively. The values are in line with the inductive effects of the halogen atoms ${ }^{2}$.

\subsection{Proton-Proton Coupling Constants}

Coupling constants are of immense use in configurational and conformational studies. Vicinal coupling constant between two protons depends on their relative positions. For example, in 1, 2 - disubstituted ethenes, the vicinal coupling constant between the olefinic protons is always larger for trans isomer 12 than for cis isomer $13^{3}$.

[3]-isopropyl - r - [2], c[6]- diphenylpiperidin-4one[16] and its oxime [17] at $400 \mathrm{MHZ}$. Analysis of the vicinal coupling constants have suggested that boat form 18 contributes to these compounds.

\section{3. ${ }^{13}$ C NMR Spectroscopy}

\section{3. $1{ }^{13} \mathrm{C}$ Chemical Shift}

${ }^{13} \mathrm{C}$ chemical shift depends on many factors. Lambert et al. ${ }^{4}$ have studied the effect of heteroatom in monoheteracyclohexanes 26 on the shifts of ring carbons. The $\alpha$ - shift is a steep function of the electronegativity of the heteroatom X. An increase byone unit in electronegativity produces a downfield shift of about $50 \mathrm{ppm}$. However, the 
effect of hetero atom electronegativity on $\beta$ and $\gamma$ carbons is small.

The $\alpha$ and $\beta$ carbons of the trans isomer appear markedly upfield suggesting that $\alpha$ and $\beta$ effects are smaller for an axial substituent than for equatorial substituent.

Buchnann 65 noticed upfield shifts in 31a relative to the equatorial counterpart $31 \mathrm{~b}$ by studying the 13C NMR Spectrum of Vinylcyclohexane at low temperature. The chemical shifts of $31 \mathrm{a}$ and $31 \mathrm{~b}$ are listed in Table 2.

\section{$3.2{ }^{13} \mathrm{C}^{-1} \mathrm{H}$ Coupling Constants}

The ${ }^{13} \mathrm{C}^{-1} \mathrm{H}$-coupling constants are useful parameters in the study of organic molecules.

One bond coupling constant ${ }^{1} \mathrm{~J}_{\mathrm{CH}}$ is given by equation $9,{ }^{5}$ where \%s represents the percentage ' $s$ ' character of the carbon hybrid orbital participating in the $\mathrm{C}-\mathrm{H}$ bond.

$$
{ }^{1} \mathrm{~J}_{\mathrm{CH}}=5 \mathrm{X}[\% \mathrm{~s}][\mathrm{Hz}]
$$

Equation [9] was later modified 79 as equation [10]

$$
{ }^{1} \mathrm{~J}_{\mathrm{CH}}=5.7 \mathrm{X}[\% \mathrm{~s}]-18.4[\mathrm{~Hz}]
$$

The ${ }^{1} \mathrm{~J}_{\mathrm{CH}}$ coupling constants in some compounds are given in Table 4.

${ }^{2} \mathrm{~J}_{\mathrm{CH}}$-coupling constants are usually small. The ${ }^{2} \mathrm{JC}_{\mathrm{H}}$ coupling constants of some compounds are given in Table 3
${ }^{3} \mathrm{~J}_{\mathrm{CH}}$-coupling constants depend on the dihedral angle. The coupling constant and dihedral angle are related by Karplus Conroy relation (eqution 11$)^{6}$

$$
{ }^{3} \mathrm{~J}_{\mathrm{CH}}=4.26-\cos \varphi+3.56 \cos 2 \varphi
$$

${ }^{3} \mathrm{~J}_{\mathrm{CH}}$-coupling constants of some compounds are given.

\section{Homonuclear Correlation Spectroscopy [HOMOCOSY]}

In this type of spectrum, ${ }^{1} \mathrm{H}$ chemical shifts along both frequency axes are correlated with each other. The ${ }^{1} \mathrm{H}$ spectrum appears along the diagonal as contours responding peak intensities. The off - diagonal contours are the cross peaks. A horizontal line drawn from a cross peak will intercept a contour on the diagonal and a vertical line from the same cross peak will intercept another contour on the diagonal with which the first diagonal contour is coupled. Thus, we can assign signals unambiguously.

\section{Heteronuclear Correlation Spectroscopy [HETCOR]}

The HETCOR spectrum correlates the peaks of ${ }^{1} \mathrm{H}$ spectrum with the peaks of ${ }^{13} \mathrm{C}$ spectrum, and shows the specific protons attached to each carbon. The ${ }^{1} \mathrm{H}$ spectrum

Table 1. ${ }^{13} \mathrm{C}$ Chemical shifts for 1 - hetera - 2,6 - diaryl - 4-cyclohexanones

\begin{tabular}{ccccc}
\hline Compound & X & C - 2 & C - 3 & C -4 \\
\hline 29a & S & 48.15 & 50.24 & 206.78 \\
30a & S & 43.78 & 48.41 & 207.75 \\
29b & O & 78.64 & 49.46 & 205.20 \\
30b & O & 73.27 & 46.19 & 205.87 \\
\hline
\end{tabular}

Table 2. One - bond coupling constants, ${ }^{1} \mathrm{~J}_{\mathrm{CH}}$

\begin{tabular}{ll}
\hline Compound & ${ }^{1} \mathrm{~J}_{\mathrm{CH}[\mathrm{Hz}]}$ \\
\hline Methane & 125.0 \\
Ethane & 124.9 \\
Propane & 114.2 \\
Chloromethane & 150.0 \\
Methanol & 141.0 \\
Benzene & 165.0 \\
\hline
\end{tabular}

Table 3. Two - bond coupling constants, ${ }^{2} \mathrm{~J}_{\mathrm{CH}}$

\begin{tabular}{lr}
\hline Compound & ${ }^{1} \mathrm{~J}_{\mathrm{CH}[\mathrm{Hz}]}$ \\
\hline Ethane & -4.5 \\
Ethene & -2.4 \\
Ethyne & 49.3 \\
Benzene & 1.0 \\
Ethanol & 26.7 \\
\hline
\end{tabular}


is presented on the vertical axis and the ${ }^{13} \mathrm{C}$ spectrum on the horizontal axis . The ${ }^{1} \mathrm{H}-{ }^{13} \mathrm{C}$ correlation is shown by the off - diagonal contours.

\section{Nuclear Overhauser and Exchange Spectroscopy [NOESY]}

Nuclear Overhauser and Exchange Spectroscopy assembles all the ${ }^{1} \mathrm{H}-{ }^{1} \mathrm{H}$ NOE spectrum effects in a molecule into a single spectrum. In a NOESY spectrum, the ${ }^{1} \mathrm{H}$ spectrum is represented by contours along the diagonal, and the off diagonal contours represent non-bonding ${ }^{1} \mathrm{H}-{ }^{1} \mathrm{H}$ interactions with protons that are nearby in space.

\section{Scope of the Present Investigation}

In the present study DAERM method and Altona's equation are used to calculate torsional angles from the reported proton-proton vicinal coupling constants of the following compounds:

$r(2), c(6)$ - diphenoxan -4- one

$\mathrm{t}$ (3)-Methyl -r(2), c(6) - diphenylpiperidin-4- one

$t$ (3)-Ethyl -r(2), c(6) - diphenylpiperidin-4- one

$\mathrm{t}$ (3)-isopropyl -r(2), c(6) - diphenylpiperidin-4- one (44)

3, 3 -dimethy -r(2), c(6) - diphenylpiperidin-4- one

A method is proposed to find whether the vicinal coupling in a - $\mathrm{CHX}-\mathrm{CH} 2$ - system represent a single conformation or an equilibrium between two or more conformations. This method is applied in conformational analysis of the following compounds:

N-Phenylcarbamoyl-r(2), c(6) - diphenylpiperidin4- one

$\mathrm{N}$-Phenylcarbamoyl-t(3) - methyl-r(2),c(6) diphenylpiperidin-4-one

N-Phenylcarbamoyl-t(3) - ethyl-r(2), c(6) diphenylpiperidin-4-one

${ }^{1} \mathrm{H}$ NMR spectra have been recorded for $\mathrm{t}(3)$-methyl -r(2), $c(7)$ - diphenylhomopiperazin-5- one (61), $t$ (3)-ethyl -r(2), c(7) - diphenyl homopiperazin-5- one (62) and t (3)-isopropyl -r(2), c(7) - diphenyl homopiperazin-5- one (63) have been recorded at $500 \mathrm{MHz}$ in DMSO- $\mathrm{d}_{6}$. The various chemical shifts and coupling constants have been extracted. These values are compared with those in $\mathrm{CDCl}_{3}$. The solvent effect is discussed.

${ }^{13} \mathrm{C}$ NMR spectra have been recorded for compound 61-63 IN DMSO $-\mathrm{d}_{6}$. The chemical shifts are compared with those in $\mathrm{CDCl}_{3}$. The solvent effect is discussed.

COSY, NOESY and ${ }^{13} \mathrm{C}^{-1} \mathrm{H}$ correlation spectra have been recorded for compounds 61-63. These are used to assign the signals unambiguously.

\section{Result and Dicussion}

\subsection{Homopiperazin - 5 - Ones}

The ${ }^{1} \mathrm{H} N M R$ spectral studies have been made on homopiperazin - 5 - ones in $\mathrm{CDCl}_{3}$. In all the cases, the benzylic protons appeared as doublets around 3.6-4.1 ppm. When there are two methylene protons adjacent to the benzylic proton, one must expect a doublet of doublets. Moreover, the methylene protons at $\mathrm{C}-6$ gave only six lines [four lines for one proton and two lines for the other]. These observations suggested that the coupling constant of the benzylic proton with one of the vicinal protons is very nearly zero.

In all the cases, the lactum $\mathrm{NH}$ proton coupled with the proton at $\mathrm{C}-3$. The negligible coupling constant of the benzylic proton with one of the methylene protons suggested a puckered chair conformation for 67 (Figure 14). $J_{6,7}$ values did not vary considerably for all these com pounds. These suggested that the conformation of - $\mathrm{CO}-$ C6 - C7 - NH - part of the ring in these compounds remained almost the same.

However, $J_{2,3}$ values of 61,62 and 63 were considerably lower than that of 67 . This was explained as follows: the ring undergoes flattening about the $\mathrm{C} 2-\mathrm{C} 3$ bond to decrease the phenyl-alkyl interaction. As a result, the ring dihedral angle about the $\mathrm{C}_{2}-\mathrm{C}_{3}$ bond will be considerably less than 60 .

The buttressing effect of alkyl group must increase the coupling constant. Since the isopropyl group has a large buttressing effect the $J_{2,3}$ value for 63 was larger than those for 61 and 62 .

The observed germinal coupling constants also proved the flattening by alkyl groups. For 67, 61, 62 and 63 , the germinal coupling constants between the methylene protons at C- 6 were $14.50,14.18,13.85$ and $13.85 \mathrm{~Hz}$, respectively. In 61, 62 and 63 this interaction is decreased by flattening at the alkyl side of the ring. 
The ${ }^{13} \mathrm{C}$ NMR spectra of homopiperazin -5 - ones were recorded in $\mathrm{CDCl}_{3}{ }^{7}$. The effects of methyl group on the chemical shifts of the ring carbons were compared with those in the corresponding piperidin - 4 - one and its oxime. It was found that the $\alpha$ - effect of methyl group is controlled by polar nature of the neighbouring group and also by ring size, but the $\beta$ - effect is affected largely by ring size.

In the present study, ${ }^{1} \mathrm{H}$ NMR and ${ }^{13} \mathrm{C}$ NMR spectra have been recorded for 61,62 , and 63 in DMSO $-\mathrm{d}_{6}$. The solvent effect is discussed.

${ }^{1} \mathrm{H}$ NMR spectra have been recorded for 62 and 63 at different concentrations. The effect of concentration is discussed. ${ }^{1} \mathrm{H}$ NMR NMR spectra have been recorded for 62 and 63 at different temperatures. The temperature effect is discussed. To assign the signals COSY, NOESY and ${ }^{13} \mathrm{C}^{-1} \mathrm{H}$ correlation spectra have been used.

The atoms in the heterocyclic ring are numbered as shown in Figure 16. The protons are labelled as amino $[\mathrm{N}-1], \mathrm{H}-2, \mathrm{H}-3$, lactum [N-4], $\mathrm{H}-6_{\mathrm{a}}, \mathrm{H}_{\mathrm{e}}$ and $\mathrm{H}-7$. Between the methylene protons at $\mathrm{C}-6$ one having large coupling with $\mathrm{H}-7$ is termed as $\mathrm{H}-6$.

\subsection{Assignment of Signals}

The triplet at $0.72 \mathrm{ppm}$ corresponds to three protons and has a coupling constant of $7.3 \mathrm{~Hz}$. Obviously, this is due to the methyl proton. The multiplet at $1.41 \mathrm{ppm}$ corresponds to two protons. This must be due to $\mathrm{CH}_{2}$ of ethyl group.

There are two peaks for the ortho aromatic protons at 8.06 and $7.96 \mathrm{ppm}$. Each of these peaks corresponds to 2 protons. These are due to ortho protons of the phenyl rings at $\mathrm{C}-2$ and $\mathrm{C}-7$. For other aromatic protons a multiplet is seen at $7.58 \mathrm{ppm}$. This corresponds to six protons.

In the NOESY spectrum shown in Plate -8 , the $\mathrm{CH}_{2}$ of ethyl group at $1.41 \mathrm{ppm}$ shows weak NOE with the peak at $3.79 \mathrm{ppm}$. Therefore, it should be due to $\mathrm{H}-3$.

The ortho aromatic proton signal at $8.05 \mathrm{ppm}$ gives NOE with the peak at $3.79 \mathrm{ppm}$. Therefore, this signal is due to the ortho protons at $\mathrm{C}-3$. The other ortho aromatic proton signal at $7.96 \mathrm{ppm}$ gives NOE with the peak at $3.90 \mathrm{ppm}$. Therefore, the peak at $3.90 \mathrm{ppm}$ is due to $\mathrm{H}-6$.

The $\mathrm{H}-6$ signal at 3.90 ppm shows NOE with the signal at $2.82 \mathrm{ppm}$. Therefore, the signal at $2.82 \mathrm{ppm}$ should be due to $\mathrm{H}-6$.

The chemical shifts are listed in Table 14 along with those found in $\mathrm{CDCl}_{3}$.
Table 14. The chemical shift values of 62 in DMSO $-\mathrm{d}_{6}$ and $\mathrm{CDCl}_{3} .114$

\begin{tabular}{lcc}
\hline Proton & DMSO $-\mathrm{d}_{6}[\mathrm{ppm}]$ & $\mathrm{CDCl}_{3}[\mathrm{ppm}]$ \\
\hline $\mathrm{NH}($ amino $)$ & $11.31[\mathrm{~d}]$ & $2.02[\mathrm{~s}]$ \\
$\mathrm{NH}$ (lactum) & $10.09[\mathrm{~d}]$ & $5.90[\mathrm{~s}]$ \\
& $8.05[\mathrm{~d}]$ & \\
Aromatic & $7.96[\mathrm{~d}]$ & $7.32[\mathrm{~m}]$ \\
& $7.58[\mathrm{~m}]$ & \\
$\mathrm{H}-7$ & $5.11[\mathrm{~s}]$ & $4.11[\mathrm{~d}]$ \\
$\mathrm{H}-2$ & $4.88[\mathrm{t}]$ & $3.77[\mathrm{~d}]$ \\
$\mathrm{H}-6_{\mathrm{a}}$ & $3.90[\mathrm{t}]$ & $3.15[\mathrm{q}]$ \\
$\mathrm{H}-3$ & $3.79[\mathrm{~s}]$ & $3.66[\mathrm{~m}]$ \\
$\mathrm{H}-6 \mathrm{e}$ & $2.82[\mathrm{~d}]$ & $2.65[\mathrm{~d}]$ \\
$\mathrm{CH}_{2}(\mathrm{Et})$ & $1.41[\mathrm{~m}]$ & $1.11[\mathrm{~m}]$ \\
$\mathrm{CH}_{3}(\mathrm{Et})$ & $0.72[\mathrm{t}]$ & $0.85[\mathrm{t}]$ \\
\hline
\end{tabular}

\section{Assignment of Signals}

The assignment of signals has been made using conventional rules. The assignments were confirmed using ${ }^{13} \mathrm{C}$, ${ }^{1} \mathrm{H}$ correlation spectrum shown in Plate- 12

$\mathrm{H}-2$ signal at $4.88 \mathrm{ppm}$ shows correlation with the peak at $64.2 \mathrm{ppm}$. Therefore, the signal at $64.2 \mathrm{ppm}$ is due to $\mathrm{C}-2, \mathrm{H}-7$ signal at $5.11 \mathrm{ppm}$ shows correlation with the signal at $60.4 \mathrm{ppm}$. Hence, signal at $60.4 \mathrm{ppm}$, being due to $\mathrm{C}-7$. $\mathrm{H}-3$ signal at $3.79 \mathrm{ppm}$ shows correlation with the peak at $52.8 \mathrm{ppm}$. It should be due to $\mathrm{C}-3$. Both $\mathrm{H}-6_{\mathrm{e}}$ signal at $3.90 \mathrm{ppm}$ and $\mathrm{h}-6_{\mathrm{a}}$ signal at $2.82 \mathrm{ppm}$ show correlation with the signal at $46.1 \mathrm{ppm}$. Therefore, it is due to $\mathrm{C}-6$.

\section{References}

1. Thomas WA. NMR (Nuclear Magnetic Resonance) Spectroscopy. Annu Rev. 1968; 1:43.

2. Bladon P. NMR (Nuclear Magnetic Resonance) Spectroscopy. Annu Rev. 1969; 2:1.

3. Thomas WA. NMR (Nuclear Magnetic Resonance) Spectroscopy. Annu Rev. 1970; 3:91.

4. Anet FAL, Anet R. Determination of organic structure from physical methods. In Nachol FC, editor. New York: Academic Press; 1971.

5. Anet FAL, Anet R. Dynamic nuclear magnetic resonance spectroscopy. In Jackman LM, Cotton FA. New York: Academic Press; 1975.

6. Lukas G. Chem France. Bull Soc. 351; 1972.

7. Tanable M, Biosynthesis spe $\neg$ cialist periodical reports. In Geissman TA, editors. London: The Chemical Society; 1973. 